REVIEW

\title{
Role of antibiotic stewardship in extending the age of modern medicine
}

\author{
M Mendelson, BSc, PhD (Cantab), MB BS, FRCP, DTM\&H \\ Division of Infectious Diseases and HIV Medicine, Department of Medicine, Faculty of Health Sciences, Groote Schuur Hospital and \\ University of Cape Town, South Africa
}

Corresponding author: M Mendelson (marc.mendelson@uct.ac.za)

Antibiotic resistance is threatening modern medicine. Overuse and misuse of antibiotics is driving resistance to such an extent that we have entered the post-antibiotic era, where some multidrug- and pandrug-resistant bacterial infections are no longer treatable. If the situation is not reversed, 10 million people will die annually of drug-resistant infections by 2050. More than just a question of mortality, such infections are causing the closure of wards, cancellation of operations, and interference with other common medical procedures that rely on antibiotics for their success. The response to this crisis requires co-ordinated international action with increased surveillance of bacterial resistance, infection prevention, and antibiotic stewardship, i.e. access to affordable, quality-assured antibiotics prescribed appropriately. This review describes antibiotic stewardship at the individual patient and programmatic level, which must be adopted by every prescriber if we are to preserve modern medicine for future generations.

S Afr Med J 2015;105(5):414-418. DOI:10.7196/SAMJ.9635

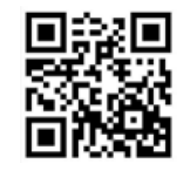

\section{Antibiotic overuse and} misuse drives resistance

A common misconception suggests that antibiotic resistance $(\mathrm{ABR})$ is a result of the introduction of antibiotics from the 1940s onwards. ABR is, however, an ancient phenomenon; bacterial resistance genes have been identified in ice samples dating back 30000 years. ${ }^{[1]}$ Naturally acquired bacterial resistance genes are propagated by the survival advantage they confer on bacteria in response to attack from naturally occurring antibacterial proteins produced by other bacteria and fungi. Resistance mechanisms may also be acquired through horizontal gene transfer of mobile genetic elements on plasmids (circular pieces of extrachromosomal DNA) that carry the resistance gene(s) between bacteria. ${ }^{[2]} \mathrm{A}$ bacterium that possesses a way of resisting an antibiotic attack has a survival advantage over bacteria that do not. In the presence of an antibiotic to which that bacterium is resistant, the resistant bacterium will be selected out in favour of bacteria that are sensitive to the antibiotic. Hence, Darwinian natural selection is being played out. The antibiotics first discovered by Fleming did not create ABR - their use has provided a survival advantage to resistant bacteria. It therefore follows that the more antibiotics one uses, the more resistance will develop.

This paradox threatens modern medicine, which relies so intimately on antibiotics for its successes. Estimates suggest that antibiotics have resulted in an additional 20 years of life expectancy. ${ }^{[3]}$ The use of antibiotics to prevent surgical site infection enables safe surgical procedures that would otherwise carry significant morbidity and mortality. ${ }^{[4]}$ Antibiotics form an integral part of the management of high-risk patients, such as the critically ill in intensive care units, those who are immunosuppressed as a result of transplantation, chemotherapy or HIV, and those with a broad spectrum of bacterial infection - from sepsis to septic shock. For every hour a person with septic shock is not being treated with an antibiotic to which the bacteria are sensitive, mortality increases by $7.8 \%{ }^{[5]}$ Mortality from antibiotic-resistant compared with antibiotic-sensitive infections is increased, as is morbidity and length of hospital stay ${ }^{[6]}$ Furthermore, resistance comes with heavy financial costs to healthcare systems; second- and third-line antibiotics are more expensive. ${ }^{[7]}$ Therefore, to limit resistance we face a critical balance between the need to use antibiotics as life-saving medicines and the need to ensure their appropriate use.

We are currently in a state of crisis. Overuse and misuse of antibiotics over the past 70 years has propelled us into a postantibiotic era. Untreatable, pandrug-resistant bacterial infections are increasingly common, ${ }^{[8,9]}$ and colonisation or infection with multidrug-resistant (MDR) bacteria has changed the risk profile of patients to such an extent that medical and surgical procedures may no longer be considered. ${ }^{[10]}$ We have engendered this global disaster by disregarding the basic tenet of antibiotic prescribing, i.e. 'access not excess', and by forgetting that, ecologically, antibiotics are a common pooled resource whose use, and exclusion of use through resistance, affects the global population rather than merely our patients or ourselves. Also, individuals and populations travel, and with them resistant bacteria such as New Delhi metallobetalactamase-1$(\mathrm{NDM}-1)^{[11]}$ or Klebsiella pneumoniae carbapenemase $(k p c)^{[12]}$ in Gram-negative bacteria, which has ensured the global spread of MDR bacteria to new, susceptible populations. People in low- and middleincome countries (LMICs), where healthcare systems are already overstretched owing to the high burden of infection, are at an even greater disadvantage than those in high-income countries (HICs).

\section{Global response to antibiotic resistance}

An international response is required to answer this crisis. The World Health Organization (WHO), whose previous calls for action went largely unheeded, ${ }^{[13,14]}$ has developed a draft global action plan (GAP) as a result of wide stakeholder consultation that will be presented at the 68th World Health Assembly in Geneva, Switzerland in May 2015 for adoption. ${ }^{[15]}$ GAP mandates member states to produce national strategic plans to combat antimicrobial resistance (AMR), with specific emphasis on antibacterial resistance. ${ }^{[1,17]}$ Simply put, there are three fundamental pillars of any strategy that must be strengthened to combat ABR. Firstly, through strengthened surveillance and reporting, we need to learn what the resistance profile of the bacteria in our local environment (community and healthcare settings) is to enable 
appropriate choice of an antibiotic that will be active against a given infection. Secondly, when a bacterium that requires treatment is identified or an empiric antibiotic(s) is needed before its identification, we must optimise the use of that antibiotic to maximise its action (antibiotic stewardship (ABS)). Lastly, we need to prevent infection before it occurs by attending to social determinants that drive infectious diseases, such as water supply and sanitation, and increase access to and coverage with vaccines. Rigorous infection control practice in healthcare settings to prevent transmission of resistant bacteria from patient to patient must be adopted, chief among which is rigorous hand hygiene. Infection prevention as it relates to $\mathrm{ABR}$ is comprehensively reviewed in this CME series by Brink ${ }^{[18]}$ and Whitelaw. ${ }^{[19]}$

The required response is as pertinent to animal and agricultural sectors as it is to human health. As an estimated $80 \%$ of all antibiotic use is in animals ${ }^{[20]}$ and its association with acquisition of resistant bacteria by humans is becoming increasingly clear, ${ }^{[21]}$ we disregard the impact of antibiotic use in the animal sector at our peril. However, for the purposes of this review, I concentrate on the essential elements of ABS as it relates to bacterial infections other than tuberculosis in humans.

\section{Antibiotic stewardship at the individual patient level}

At an individual patient level, a single fundamental question needs to be asked before any antibiotic is prescribed: 'Does this patient have a bacterial infection that requires an antibiotic?' (Fig. 1.) While particularly pertinent to primary care prescribers and the continued unnecessary use of antibiotics for viral upper respiratory tract infections (URTIs), it applies equally to febrile patients admitted to healthcare institutions at all levels. The identification of intensive care patients in the public and private sectors in South Africa (SA) who were on up to 10 different antibiotics concurrently, testifies to this and the need to realise that collective action is needed. ${ }^{[22]}$

Although simpler for patients with a clear source of infection, the question of whether a patient has a bacterial infection becomes more complex when related to an undifferentiated fever, i.e. one that lacks a clear site of origin. Fear of missing a bacterial infection is a strong motivator for prescribing antibiotics, ${ }^{[23]}$ whereas having access to diagnostic tests, ideally those at point-ofcare (POC) to help differentiate the cause of fever, increases appropriate antibiotic use. ${ }^{[24,25]}$ Access to a POC malaria rapid diagnostic test in Zambia led to a four-fold reduction in inappropriate antimalarial prescribing, and a five-fold increase in the appropriate use of antibiotics for pneumonia. ${ }^{[25]}$ Furthermore, when diagnostic and resistance information is provided in a single test, not only may a diagnosis be established, but the time to appropriate antibiotic use reduced. The automated real-time nucleic acid amplification system Xpert MTB/RIF, which can confirm the presence of tuberculosis and its sensitivity to rifampicin within 2 hours, is one such example. ${ }^{[26]}$ Similarly, rapid POC or close to POC non-culture-based tests for antibioticresistant bacteria other than Mycobacterium tuberculosis are urgently needed, particularly in LMICs with poor access to assured quality diagnostic services.

When the source of infection is clear, but the microbial aetiology is not, biomarkers such as C-reactive protein (CRP) and procalcitonin (PCT) may be useful tools for specific infections. Both $\mathrm{CRP}^{[27,28]}$ and $\mathrm{PCT}^{[29,30]}$ have demonstrated utility in differentiating bacterial from viral acute respiratory infection (ARI) in developed countries, and for PCT its use has been estimated to confer substantial economic gains (USD1.6 billion (ZAR18.8 billion) savings if used across the US health sector) in HICs. ${ }^{[31]}$ In a high tuberculosis-prevalence country such as SA, the utility of CRP and PCT is less clear for ARI, as both are increased in tuberculosis. Furthermore, in a resourcechallenged healthcare setting, PCT, which currently costs in excess of ZAR300 per test, is costly, particularly when used incorrectly. ${ }^{[32]}$

Once the decision has been made to treat with an antibiotic, it is imperative that, whenever possible, adequate specimens are sent to the laboratory to enable identification of the bacteria causing infection and, critically, its sensitivity profile to antibiotics (the antibiogram) before the antibiotic is administered. The likelihood of adverse effects of broad-spectrum antibiotics, whose use is commonly indicated at the start of treatment, is greater than those of directed, narrow-spectrum antibiotics that can be used once sensitivities are known. An antibiogram is a prerequisite for safe de-escalation from a broad- to narrow-spectrum antibiotic. Without it, the prescriber runs the risk of

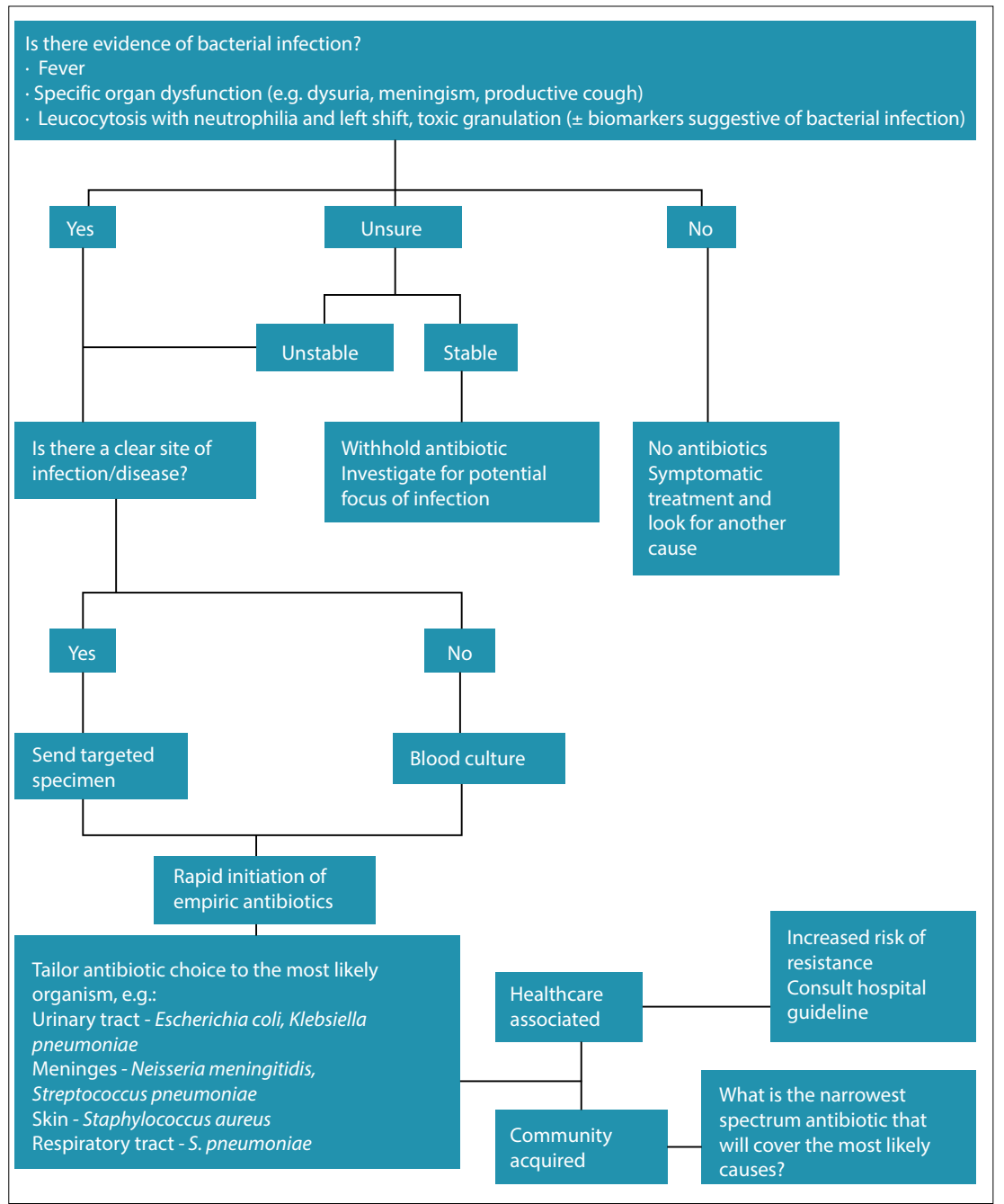

Fig. 1. Algorithm to determine whether a patient has a bacterial infection. 
using a resistant or partially active antibiotic, which may negatively affect the patient's treatment. Whenever possible, a specimen from the probable site of infection should be sent to the laboratory. If no focus is evident, one or more correctly taken blood cultures are required (Fig. 1) ${ }^{[33]}$ For blood cultures, the volume of blood inoculated is critical in determining yield. In an unselected cohort of adult patients requiring blood culture in the Emergency Department at Groote Schuur Hospital, Cape Town, all cultures were negative if $<2 \mathrm{~mL}$ of blood were inoculated. The yield doubled if $10-12 \mathrm{~mL}$ were inoculated compared with $2-8 \mathrm{~mL}$ (T Boyles - personal communication).

Once appropriate cultures have been sent, considering the checklist presented in Box 1 can optimise prescribing. The empiric choice of an antibiotic is determined by the probable identity of the infecting organism and the likelihood of it carrying a resistance gene. For example, Gram-negative Enterobacteriaceae (Escherichia coli and Klebsiella pneumoniae) commonly cause urinary tract infections (UTIs); therefore, an antibiotic with a spectrum of activity against Gram-negative bacteria is advised. Resistance to commonly used Gram-negative antibiotics for UTI in community-acquired infections in SA is generally still low, but does vary geographically. Therefore, an antibiotic such as an aminoglycoside or ciprofloxacin would be an acceptable empiric choice. However, in SA, hospital-acquired UTI due to Enterobacteriaceae is characterised by high levels of extendedspectrum beta-lactamase production, rendering many resistant to firstline antibiotics, and forcing the use of second-line, broader-spectrum antibiotics.
The optimal dose of an antibiotic depends on a number of factors, including the pharmacodynamic and pharmacokinetic properties associated with individual antibiotics, the patient's body weight, renal function, and, less commonly, hepatic function. Dosing of many antibiotics is weight dependent, e.g. vancomycin (Box 2), whose dosing frequency must be guided by therapeutic drug monitoring. A lack of attention to weight-based dosing and renally determined dosing frequency represents a common antibiotic prescribing pitfall. Pharmacokinetics play an especially important role in the critically ill patient in whom the volume of distribution may increase, augmented renal clearance may be present, and hypoalbuminaemia may alter the ratio of bound v. unbound antibiotic. Hence, dose must be carefully considered to optimise the effect of the antibiotic, particularly in those who are critically ill.

For many prescribers, determining the duration of an antibiotic course is a matter of what is familiar or easy, and bears little or no relation to trial evidence or national guidelines. Therefore, many antibiotic courses are prescribed for $\geq 1$ week. For example, experience from our ABS programme at Groote Schuur Hospital indicated that the vast majority of patients in the Emergency Department who were prescribed ceftriaxone received a prescription for an antibiotic for 2 weeks, irrespective of the indication (M Mendelson - unpublished observations). Unfortunately, a strong evidence base for antibiotic duration is often lacking, meaning that decisions are based not on randomised controlled trials, but on small observational studies or expert opinion. In SA, the Essential Drugs List (EDL) and Structured Treatment Guidelines (STGs) ${ }^{[34]}$

\section{Box 1. Checklist for optimal antibiotic prescribing}

1. Drug - which is the narrowest spectrum antibiotic that I can use to treat this bacterial infection?

2. Dose - many antibiotics require weight-based dosing and their dosing depends on renal and/or hepatic function

3. Dose frequency - dependent on the half-life of the drug and whether the action of the antibiotic depends on the time above the MIC or the area under the concentration/time curve. Calculation of the dosing frequency may require therapeutic drug monitoring, such as for vancomycin or aminoglycosides

4. Duration - should be dictated by evidence from randomised controlled trials whenever possible. Expert opinion from national and international guidelines should be consulted where evidence is weak

5. Route - most antibiotics have good oral bioavailability, but some infections will require intravenous therapy either for the whole or part of the course 6. De-escalation - applies to the spectrum of antibiotic use and route of administration. All attempts to convert early from parenteral to oral use should be made MIC = minimum inhibitory concentration

Box 2. Vancomycin dosing

All patients should be weighed and GFR estimated

All patients should receive a loading dose of $25-30 \mathrm{mg} / \mathrm{kg}$

All subsequent doses should be $10-15 \mathrm{mg} / \mathrm{kg}$ (unless inadequate trough levels achieved)

Dosing interval and measurement of trough concentrations depends on eGFR

\begin{tabular}{lll}
\hline eGFR $(\mathbf{m L} / \mathbf{m i n})$ & Dosing interval (hours) & Measurement of trough concentrations \\
\hline$>80$ & 12 & Before 3rd dose \\
$50-79$ & 24 & Before 3rd dose \\
$55-49$ & 36 & Before 2nd dose \\
$25-34$ & 48 & Before 2nd dose \\
$<25$, haemodialysis or chronic ambulatory & When trough level & 3 days after loading dose \\
peritoneal dialysis & $<15 \mu \mathrm{g} / \mathrm{mL}$
\end{tabular}

Aim for trough concentration of $10-20 \mu \mathrm{g} / \mathrm{mL}$, except for osteitis or endocarditis, or if $\mathrm{MIC}>1 \mu \mathrm{g} / \mathrm{mL}$, when trough should be $15-20 \mu \mathrm{g} / \mathrm{mL}$

If trough is too low - increase the dose

If trough is too high - increase the dosing interval

eGFR = estimated glomerular filtration rate. 


\section{Box 3. Criteria for switching from parenteral to oral antibiotic route $\mathrm{e}^{[61,62]}$}

1. No indication requiring long-term parenteral antibiotic use: endocarditis, meningitis, central nervous system infection, osteomyelitis, prosthetic material infection, Staphylococcus aureus bacteraemia, undrained or undrainable abscess and neutropenic fever

2. Patient is able to take oral medications and lacks indications of potential malabsorption

3. An alternative oral antibiotic is available

4. Temperature $<38^{\circ} \mathrm{C}$ for $\geq 24$ hours

5. Clinically improving or remaining stable

may guide prescribers. The SA Antibiotic Stewardship Programme (SAASP) guidelines for antibiotic prescribing in adults, ${ }^{[35]}$ which is aligned to the EDL and STGs, provide an algorithmic approach to prescribing and further information on treatment duration. It is now available as the 'SAASP' App across platforms.

The route of administration of an antibiotic depends on the site of infection, how rapidly high drug levels need to be achieved, and ability of a patient to absorb an oral antibiotic. Some infections, such as bacterial meningitis, osteomyelitis or endocarditis, require high levels of antibiotic to be delivered to the site of infection, and necessitate parenteral antibiotics for all or the majority of the course. De-escalation to an oral antibiotic is a key principle of stewardship, as this obviates the need for vascular access and enables removal of a peripheral or central line. This reduces the risk of central line-associated bloodstream infections (CLABSI) or its peripheral counterpart. Prevention of CLABSI reduces morbidity, length of hospital stay and, ultimately, mortality. ${ }^{[36]}$ Box 3 gives guidance for safe de-escalation from the parenteral to oral route.

\section{Antibiotic stewardship at} the programmatic level

At a programmatic level, interventions to reduce antibiotic prescribing and improve microbial outcome tend to be either restrictive (limit how a prescriber prescribes) or persuasive (advise the prescriber or give feedback about how they prescribed).

Approximately $80 \%$ of antibiotics used in humans are prescribed in primary care. ${ }^{[37,38]}$ The success of interventions at the community level depends in part on the barriers to change in that particular community and differs in countries and across borders. A meta-analysis of 39 studies of interventions to improve antibiotic prescribing in ambulatory patients concluded that multifaceted interventions are most effective at achieving overall reduction in use, while printed educational material or feedback and audit were of little value. ${ }^{[39]}$ Interactive educational sessions outperformed the didactic approach, and collaborative educational meetings between

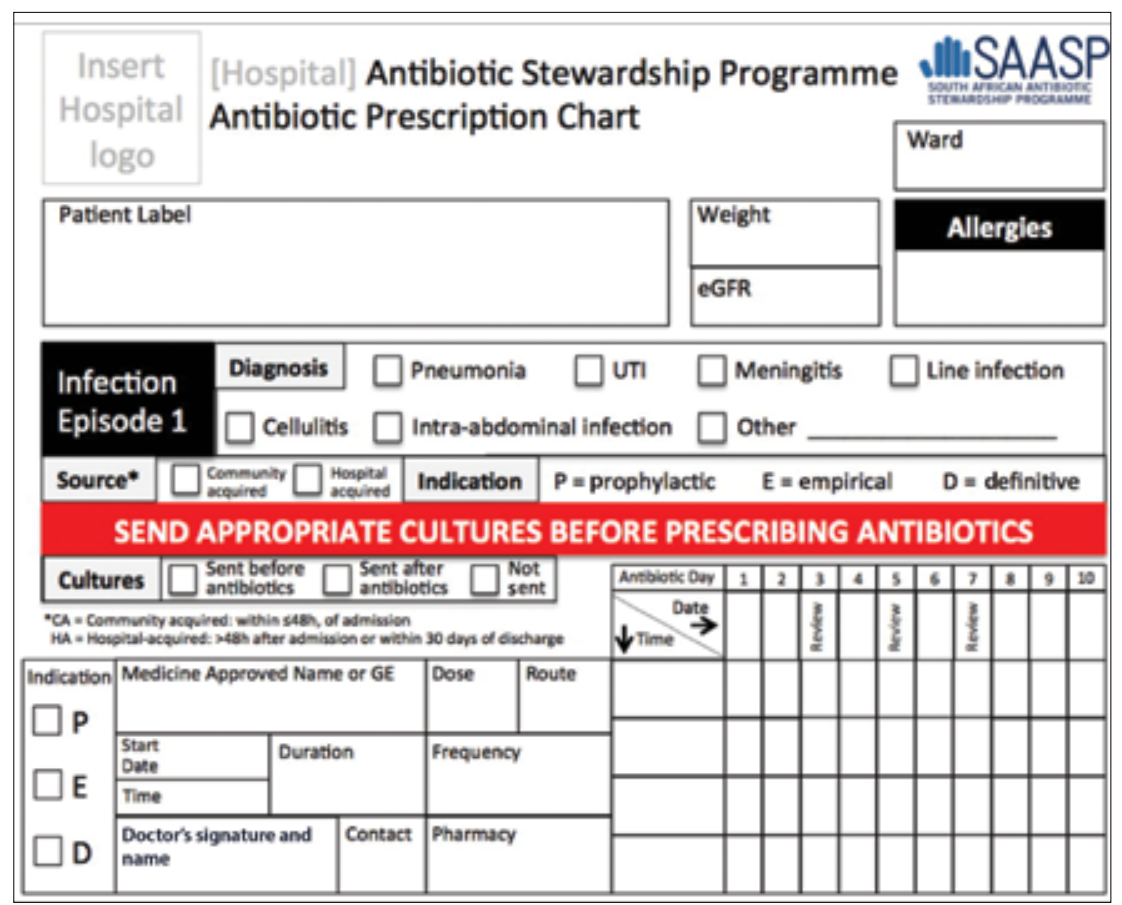

Fig. 2. South African Antibiotic Stewardship Programme prescription chart.

different groups involved in prescribing, i.e. a multidisciplinary community stewardship approach, showed promising reductions in antibiotic prescribing. ${ }^{[40]}$ Combining teaching of primary care clinicians in enhanced consulting skills and the introduction of POC CRP into their practices, had an additive effect on appropriate, safe antibiotic prescribing, which was cost-effective. ${ }^{[28,41]}$ The use of delayed prescriptions effectively reduced antibiotic use without increasing mortality. ${ }^{[42-44]}$ All of these interventions are potentially transferable to LMICs, including SA.

Successful interventions to reduce prescribing in hospitalised patients have also been the subject of a Cochrane review. ${ }^{[45]}$ Poor study designs in many investigations limited the number of studies included in the analysis to $20 \%$. There were no direct comparative studies between persuasive and restrictive interventions, but a metaanalysis of interrupted time series studies allowed comparison. Interestingly, restrictive interventions (compulsory order forms, expert approval, removal by restriction and review and change) were more effective than persuasive (dissemination of educational material, reminders, audit and feedback, and educational outreach) interventions in the first 6 months; yet, there was no difference in the longer term at 12 and 24 months. Whether combinations of intervention type would have a sustained effect needs to be investigated.

It is notable that none of the studies included in the Cochrane review was from Africa. ABS has only recently been formally introduced in SA as a change mechanism, led by SAASP since 2012 . One study published to date has adopted two persuasive interventions to augment restrictive practices that were already in place at a central hospital in Cape Town; ${ }^{[32]}$ ABS ward rounds and a dedicated antibiotic prescription chart were included in a trial in two general medical wards for a 12-month period, using the previous intervention-free year as comparator. Weekly multidisciplinary ward rounds involved the prescribing physicians, an infectious diseases specialist, microbiologist, infection control officer, and pharmacist. The charts and case 
reports of each patient on a single ward, alternating weekly, were reviewed. Antibiotic use was reduced by $19.6 \%$ without an increase in inpatient mortality or 30-day readmission rate. Although not a primary objective of the study, the intervention resulted in a $35 \%$ reduction in antibiotic budget. This type of multidisciplinary team is unlikely to be reproducible across SA and most developing country settings; however, a prescriber and pharmacist can form the nucleus of any such stewardship team.

A dedicated antibiotic prescription chart in the study by Boyles et al. ${ }^{[32]}$ was designed to focus the prescriber's attention on the indication for prescribing antibiotics, whether the infection was community or hospital acquired, and provided strong messaging to trigger appropriate sample(s) to be sent for culture (Fig. 2). Antibiotic prescribing was divided into infection episodes - if a patient developed a second or third bacterial infection in hospital, the prescriber would have to go through the same process again, and the antibiotics used to treat that infection could immediately be identified for review and audit. The use of choice architecture, which describes the way in which decisions can be influenced by how choices are presented, ${ }^{[46]}$ was recently used to improve anti-infective prescribing in a comparative study from a large UK teaching hospital. ${ }^{[4]}$

Through its national strategic plan for AMR, ${ }^{[48]}$ SA has national core standards for antimicrobial stewardship (and for infection prevention control) that will be monitored by the Office of Health Standards and Compliance. These standards include the requirement for stewardship committees and teams in all our hospitals and at district level. A clear roadmap for change is being implemented.

\section{Barriers to antibiotic stewardship}

Behaviour modification is a major factor in rectifying poor prescribing practice. Inappropriate prescribing is driven by a complex set of prescriber and patient behaviours. At the most basic level, community prescribing is often influenced by prescribers who perceive that their patients will be dissatisfied should they not receive an antibiotic. This is especially evident in how doctors perceive parental expectations. ${ }^{[49]}$ Patient expectations of receiving an antibiotic, particularly for ARI, is often high, and these have a significant influence on prescribing, even when the prescriber believes that an antibiotic is unnecessary. ${ }^{[5,51]}$

Raising public awareness to the risks posed and drivers of ABR is an important intervention. Yet, not all campaigns have been successful ${ }^{[52]}$ national campaigns in different European countries have had mixed results, with those in Germany, Spain, Greece and the UK being unsuccessful in leading to important reductions in community antibiotic use or knowledge about appropriate use, as opposed to those in Sweden, Norway, France and Belgium. Successful national campaigns are characterised by a multifaceted nature and repetition over several years. Unfortunately, there seems to be no simple relationship between knowledge and appropriate use; in a face-to-face household survey of 10981 randomly selected UK adults in 2003, multivariate analysis found that better knowledge in women was associated with being more likely to give an antibiotic to someone else for whom it was not prescribed. ${ }^{[53]}$ This endorses the fact that behaviour change is complex and more than merely about providing information.

In terms of creating public behavioural change, despite media campaigns being more successful at disseminating information, medical professionals are more successful in changing patient behaviour. ${ }^{[54]}$ Potential behavioural changes in community prescribers include improving their belief in the consequences of overprescribing and addressing their concerns around the consequences of not prescribing. Encouraging patients to adopt self-care for symptomatic relief of URTIs by consulting pharmacists instead of requesting antibiotics from doctors and greater mentoring of patients on their antibiotic use have the potential for creating change in antibiotic use at the community level.

To enable good stewardship, prescribers must have access to affordable antibiotics of assured quality. Producing a new antibiotic pipeline is not in itself the answer to the ABR problem, as resistance has developed within 16 years of every antibiotic introduced to date ${ }^{[55]}$ penicillin resistance was first identified 3 years before the antibiotic was introduced. However, lack of access to antibiotics is a major cause of mortality, mainly in children $<5$ years of age, of whom more currently die of pneumonia owing to a lack of available treatment than of ABR. Substandard and falsified antimicrobials have undermined prescribing in these countries, as has the lack of affordable medicines, whereas the use of generic medicines has successfully driven down cost. ${ }^{[56]}$ Generics produced locally to rigorous good manufacturing practice standards may enhance access to quality-assured antibiotics and thus save lives ${ }^{[57-59]} \mathrm{A}$ strong medicine regulatory authority is a prerequisite to ensure the success of a generic antimicrobial policy.

\section{Conclusion}

The development of ABR cannot be prevented, but the extent to which it impacts on modern medicine can be altered through access to assured-quality, affordable antibiotics used in an appropriate manner. The onus is on every prescriber to become an antibiotic steward, ensuring that an antibiotic is only prescribed for a bacterial infection that requires treatment, and that the use of that antibiotic is optimised at an individual patient level. Programmatically, ABS must be developed as part of a national plan along with enhanced surveillance, reporting and infection prevention initiatives. Behavioural change programmes aimed at supporting prescribers and changing patient expectations are critical interventions, as is the need for increased access to diagnostic services and the development of POC or near-POC rapid diagnostics that couple pathogen and resistance information.

If we are to alter the course of history, and prevent a situation where 10 million people die annually from antibiotic-resistant infections by $2050,{ }^{[60]}$ prescribers and public alike need to join the international community in change to preserve this precious resource.

\section{References}

1. D'Costa VM, King CE, Kalan L, et al. Antibiotic resistance is ancient. Nature 2011;477(7365):457-461. [http://dx.doi.org/10.1038/nature10388]

2. Barlow M. What antimicrobial resistance has taught us about horizontal gene transfer. Methods Mo Biol 2009;532:397-411. [http://dx.doi.org/10.1007/978-1-60327-853-9_23]

3. United Kingdom Government. Infections and the rise of antimicrobial resistance. Annual Report of the Chief Medical Officer 2011;2. https://www.gov.uk/government/uploads/system/uploads/attachment data/file/138331/CMO_Annual_Report_Volume_2_2011.pdf (accessed 2 February 2015).

4. Awad SS. Adherence to surgical care improvement project measures and post-operative surgical site infections. Surg Infect (Larchmt) 2012;13(4):234-237. [http://dx.doi.org/ 10.1089/sur.2012.131]

5. Kumar A, Roberts D, Wood KE, et al. Duration of hypotension before initiation of effective Kumar A, Roberts D, Wood KE, et al. Duration of hypotension before initiation of effective
antimicrobial therapy is the critical determinant of survival in human septic shock. Crit Care Med 2006;34(6):1589-1596.

6. Kayange M, Kamugisha E, Mwizamholya DL, Jeremiah S, Mshana SE. Predictors of positive blood culture and deaths among neonates with suspected neonatal sepsis in a tertiary hospital, MwanzaTanzania. BMC Pediatr 2010;10:39. [http://dx.doi.org/10.1186/1471-2431-10-39]

7. World Health Organization (WHO). WHO Policy Perspective 2005, adapted from WHO Model Formulary, WHO Clinical Guidelines and Management Sciences for Health's 2004 International Drug Price Indicator Guide. http://www.who.int/management/anmicrobialresistance.pdf (accessed 2 March 2015)

8. Walsh TR, Toleman MA. The emergence of pan-resistant Gram-negative pathogens merits a rapid global political resonse. J Antimicrob Chemother 2012;67:1-3. [http://dx.doi.org/10.1093/jac/dkr378] Migliori GB, De Iaco G, Besozzi G, Centis R, Cirillo DM. First tuberculosis cases in Italy resistant to al tested drugs. Euro Surveill 2007;12(5):E070517.1.

10. Smith R, Coast J. The true cost of antimicrobial resistance. BMJ 2013;346:f1493. [http://dx.doi. org/10.1136/bmj.f1493]

11. Kumarasamy KK, Toleman MA, Walsh TR, et al. Emergence of a new antibiotic resistance mechanism in India, Pakistan, and the UK: A molecular, biological, and epidemiological study. Lancet Infect Dis 2010;10(9):597-602. [http://dx.doi.org/10.1016/S1473-3099(10)70143-2]

12. Nordmann P, Cuzon G, Naas T. The real threat of Klebsiella pneumoniae carbapenemase-producin bacteria. Lancet Infect Dis 2009;9(4):228-236. [http://dx.doi.org/10.1016/S1473-3099(09)70054-4]

13. World Health Assembly. World Health Assembly Resolution WHA51.17. Emerging and othe communicable diseases: Antimicrobial resistance. http://apps.who.int/medicinedocs/documents/s16334e/ s16334e.pdf (accessed 2 February 2015).

14. World Health Assembly. World Health Assembly Resolution WHA58.27. Improving the containment of antimicrobial resistance. http://www.searo.who.int/entity/medicines/topics/wha_58_27.pdf (accessed 2 February 2015) 
15. World Health Organization. Draft Global Action Plan for Antimicrobial Resistance. http://apps.who. int/gb/ebwha/pdf_files/EB136/B136_20-en.pdf (accessed 13 March 2015).

16. Mendelson M, Matsoso MP. A global call for action to combat antimicrobial resistance: Can we get it right this time? S Afr Med J 2014;104(7):478-479. [http://dx.doi.org/10.7196/samj.8534]

17. Mendelson M, Matsoso MP. The World Health Organization Global Action Plan for antimicrobial resistance. S Afr Med J 2015;105(5):325. [http://dx.doi.org/10.7196/SAMJ.9644]

18. Brink AJ, Richards GA. Use of vaccines as a key antimicrobial stewardship strategy. S Afr Med J 2015;105(5):421. [http://dx.doi.org/10.7196/SAMJ.9651]

19. Whitelaw AC. Role of infection control in combating antibiotic resistance. S Afr Med J 2015;105(5):421 [http://dx.doi.org/10.7196/SAMJ.9650]

20. United States Food and Drug Administration. Summary report on antimicrobials sold or distributed for use in food-producing animals. Washington, DC: Department of Health and Human Services, 2009.

21. Rinsky JL, Nadimpalli M, Wing S, et al. Livestock-associated methicillin and multidrug resistan Staphylococcus aureus is present among industrial, not antibiotic-free livestock operation workers in North Carolina. PLoS One 2013;8(7):e67641. [http://dx.doi.org/10.1371/journal.pone.0067641]

22. Paruk F, Richards G, Scribante J, Bhagwanjee S, Mer M, Perrie H. Antibiotic prescription practices and their relationship to outcome in South Africa: Findings of the prevalence of infection in South African their relationship to outcome in South Africa: Findings of the preval
intensive care units (PISA) study. S Afr Med J 2012:102(7):613-616.

23. Kotwani A, Wattal C, Katewa S, Joshi PC, Holloway K. Antibiotic use in the community: What factors influence primary care physicians to prescribe antibiotics in Delhi, India. Family Practice 2010:1-7. [http://dx.doi.org/10.1093/fampra/cmq059]

24. Shakely D, Elfving K, Aydin-Schmidt B, et al. The usefulness of rapid diagnostic tests in the new contex of low malaria transmission in Zanzibar. PLoS One 2013;8(9):e72912. [http://dx.doi.org/10.1371/ journal.pone.0072912]

25. Yeboah-Antwi K, Pilangana P, MacLeod WB, et al. Community case management of fever due to malaria and pneumonia in children under five in Zambia: A cluster randomized controlled trial. PLoS Medicine 2010;7(9):e1000340. [http://dx.doi.org/10.1371/journal.pmed.1000340]

26. Denkinger C, Kik S, Pai M. Robust, reliable and resilient: Designing molecular tuberculosis tests for microscopy centres in developing countries. Expert Rev Mol Diag 2013;13(8):763-767.

27. Huang Yl, Chen R, Wu T, Wei X, Guo A. Association between point-of-care CRP testing and antibiotic prescribing in respiratory tract infections: A systematic review and meta-analysis of primary care studies. Br J Gen Pract 2013;63(616):e787-94. [http://dx.doi.org/10.3399/bjgp13X674477]

28. Cals JWL, Ament AJHA, Hood K, et al. C-reactive protein point of care testing and physician communication skills training for lower respiratory tract infections in general practice: Economic communication skills training for lower respiratory tract infections in gener,

29. Briel M, Schuetz P, Mueller B, et al. Procalcitonin-guided antibiotic use vs a standard approach for acute respiratory tract infections in primary care. Arch Intern Med 2008;168(18):2000-2007. [http://

30. Schuetz P, Christ-Crain M, Thomann R, et al. Effect of procalcitonin-based guidelines vs standard guidelines on antibiotic use in lower respiratory tract infections. The proHOSP randomized controlled trial. JAMA 2009;302(10):1059-1066

31. Schuetz P, Balk R, Briel M, et al. Economic evaluation of procalcitonin-guided antibiotic therapy in acute respiratory infections: A US health system perspective. Clin Chem Lab Med 2015;53(4):583-592. [http://dx.doi.org/10.1515/cclm-2014-1015]

32. Boyles TH, Whitelaw A, Bamford C, et al. Antibiotic stewardship ward rounds and a dedicated prescription chart reduce antibiotic consumption and pharmacy costs without affecting inpatien mortality or re-admission rates. PLOS One 2013.8(12) e79747. [http//dx doi org/10.1371/journt pone.0079747]

33. Ntusi N, Aubin L, Oliver S, Whitelaw A, Mendelson M. Guideline for the optimal use of blood cultures S Afr Med J 2010;100(12):839-843.

34. Department of Health. Essential Drugs List and Structured Treatment Guidelines. http://wwwhealth. gov.za (accessed 24 March 2015).

35. South African Antibiotic Stewardship Programme. A Pocket Guide to Antibiotic Prescribing for Adults in South Africa, 2015. http://www.fidssa.co.za/images/SAASP_Antibiotic_Gudidelines_2015. pdf (accessed 2 March 2015)

6. The Joint Commission. Preventing Central Line-Associated Bloodstream Infections: A Global Challenge, a Global Perspective. Oak Brook, IL: Joint Commission Resources, 2012. http://www. PreventingCLABSIs.pdf (accessed 24 March 2015).

37. Goossens H, Ferech M, Vander Stichele R, Elseviers M; ESAC Project Group. Outpatien antibiotic use in Europe and association with resistance: A cross-national database study. Lancet 2005;365(9459):579-587.

38. Wise R. The relentless rise of resistance? I Antimicrob Chemother 2004;54(2):306-310.
39. Arnold SR, Straus SE. Interventions to improve antibiotic prescribing practices in ambulatory care. Cochrane Database Syst Rev 2005;19(4):CD003539.

40. Welschen I, Kuyvenhoven MM, Hoes AW, Verheij TJ. Effectiveness of a multiple intervention to reduce antibiotic prescribing for respiratory tract symptoms in primary care: Randomised controlled trial. BMJ 2004;329(7463):431. [http://dx.doi.org/10.1136/bmj.38182.591238.EB]

41. Little P, Stuart B, Francis N, et al. Effects of internet-based training on antibiotic prescribing rates for acute respiratory-tract infections: A multinational, cluster, randomised, factorial, controlled trial. Lancet 2013;382(9899):1175-1182. [http://dx.doi.org/10.1016/S0140-6736(13)60994-0]

42. Arroll B, Kenealy T, Kerse N. Do delayed prescriptions reduce the use of antibiotics for the common cold? A singleblind controlled trial. Journal of Family Practice 2002;51:324-328

43. Dowell J, Pitkethly M, Bain J, Martin S. A randomised controlled trial of delayed antibiotic prescribing as a strategy for managing uncomplicated respiratory tract infection in primary care. Br J Gen Pract 2001;51:200-205

44. Little P, Gould C, Williamson I, Moore M, Warner G, Dunleavy J. Pragmatic randomised controlled trial of two prescribing strategies for childhood acute otitis media. BMJ 2001;322:336-342.

45. Davey P, Brown E, Charani E, et al. Interventions to improve antibiotic prescribing practices for hospital inpatients. Cochrane Database Syst Rev 2013;(4):CD003543. [http://dx.doi.org/ 10.1002/14651858. CD003543.pub3]

46. Thaler R, Sunstein C. Nudge: Improving Decisions About Health, Wealth and Happiness. New Haven, Conn.: Yale University Press, 2008.

47. King D, Jabbar A, Charani E, et al. Redesigning the 'choice architecture' of hospital prescription charts: A mixed methods study incorporating in situ simulation testing. BMJ Open 2014;4:e005473. [http:// dx.doi.org/10.1136/bmjopen-2014 005473

48. Department of Health. Antimicrobial Resistance National Strategy Framework, 2014-2024. Pretoria: Department of Health, 2014. http://www.health.gov.za (accessed 24 March 2015).

49. Mangione-Smith R, McGlynn EA, Elliott MN, Krogstad P, Brook RH. The relationship between perceived parental expectations and pediatrician antimicrobial prescribing behavior. Pediatrics 1999;103:711-718.

50. Macfarlane J, Holmes W, Macfarlane R, Britten N. Influence of patients' expectations on antibiotic management of acute lower respiratory tract illness in general practice: Questionnaire study. BMJ 1997;315(7117):1211-1214

51. Hoffman D, Botha J. An assessment of factors influencing the prescribing of antibiotics in acute respiratory illness: A questionnaire study. S A Fam Pract 2003;45(6):20-24.

52. Huttner B, Goossens $\mathrm{H}$, Verheij T, Harbarth $\mathrm{S}$. Characteristics and outcomes of public campaigns aimed at improving the use of antibiotics in outpatients in high-income countries. Lancet Infect Dis 2010;10(1):17-31. [http://dx.doi.org/10.1016/S1473-3099(09)70305-6]

53. McNulty CAM, Boyle P, Nichols T, Clappison P, Davey P. Don't wear me out - the public's knowledge of and attitudes to antibiotic use. J Antimicrob Chemother 2007;59:727-738. [http://dx.doi.org/10.1093/ ac/dkl558]

54. Pinder R, Sallis A, Berry D, Chadborn T. Behaviour change and antibiotic prescribing in healthcare settings. Literature review and behavioural analysis. https://www.gov.uk/government/publications/ antibiotic-prescribing-and-behaviour-change-in-healthcare-settings (accessed 1 March 2015).

55. Centers for Disease Control and Prevention. Antibiotic resistance threats in the United States, 2013. http:// www.cdc.gov/durgresistnace/threat-report-2013/pdf/ar-threats-2013-508.pdf (accessed 3 March 2015).

56. Cameron A, Ewen M, Ross-Degnan D, Ball D, Laing R. Medicine prices, availability, and affordability in 36 developing and middle-income countries: A secondary analysis. Lancet 2009;373(9659):240-249.

7. Kaplan WA, Ritz LS, Vitello M, Wirtz VJ. Policies to promote use of generic medicines in low and middle income countries: A review of published literature, 2000-2010. Health Policy 2012:106(3):211224. [http://dx.doi.org/10.1016/j.healthpol.2012.04.015]

58. Kaplan WA, Wirtz VJ, Stephens P. The market dynamics of generic medicines in the private sector of 19 low and middle income countries between 2001 and 2011: A descriptive time series analysis. PLoS One 2013;8(9):e74399. [http://dx.doi.org/10.1371/journal.pone.0074399]

59. Narsai K, Williams A, Mantel-Teeuwisse AK. Impact of regulatory requirements on medicine registration in African countries - perceptions and experiences of pharmaceutical companies in South Africa. South Med Rev 2012;5(1):31-37.

60. O'Neill J, chairman. The Review on Antimicrobial Resistance, December 2014. http://amr-review.org (accessed 2 January 2015).

61. McLaughlin CM, Bodasing N, Boyter AC, Fenelon C, Fox JG, Seaton RA. Pharmacy-implemented guidelines on switching from intravenous to oral antibiotics: An intervention study. QJM 2005;98(10):745-752.

62. Mertz D, Koller M, Haller P, et al. Outcomes of early switching from intravenous to oral antibiotics on medical wards. J Antimicrob Chemother 2009;64(1):188-199. [http///dx doi org/10.1093/jac/dkp131] 